Original

\title{
Fully solution-processed zinc oxide MIS capacitors by ultrasonic spray pyrolysis in air ambient
}

\author{
Miguel A. Dominguez ${ }^{\mathrm{a}, *}$, Abdu Orduña-Diaz ${ }^{\mathrm{b}}$ \\ ${ }^{a}$ Centro de Investigaciones en Dispositivos Semiconductores, Instituto de Ciencias, Benemerita Universidad Autónoma de Puebla (BUAP), Puebla 72570, Mexico \\ ${ }^{\mathrm{b}}$ Centro de Investigación en Biotecnología Aplicada (CIBA), Instituto Politécnico Nacional, Tlaxcala, Tlaxcala 72197, Mexico
}

Received 10 August 2016; accepted 9 January 2017

Available online 1 June 2017

\begin{abstract}
In this work, the fabrication and characterization of fully solution-processed zinc oxide metal-insulator-semiconductor (MIS) capacitors by ultrasonic spray pyrolysis (USP) are presented. Fluorine tin oxide by USP was used as transparent electrode, while spin-on glass by spin-coating was used as dielectric and zinc oxide by USP was used as active layer. Also, the zinc oxide film was characterized using photoluminescence spectroscopy, X-ray diffraction and Fourier transform infrared spectroscopy. The MIS capacitors were fabricated over glass slides and were highly transparent in the visible range, which makes their use feasible in transparent electronics. Employing capacitance-voltage and current-voltage measurements, the MIS capacitors were characterized.

(C) 2017 Universidad Nacional Autónoma de México, Centro de Ciencias Aplicadas y Desarrollo Tecnológico. This is an open access article under the CC BY-NC-ND license (http://creativecommons.org/licenses/by-nc-nd/4.0/).
\end{abstract}

Keywords: MIS capacitors; Solution-processes; Transparent electronics

\section{Introduction}

In recent years, the development of transparent electronics has achieved considerable progress since wearable electronics, transparent circuitry, e-paper, solar cells and more (Bashir et al., 2009; Langley et al., 2013; Zhu, Fang, Preston, Li, \& Hu, 2014). Although the recent development in thin-film transistors (TFTs) has been very important to enable this technology, it is necessary to develop other basic devices such as transparent capacitors. These basic devices could work as sensors, energy storage from solar cells, memory devices and charge-discharge capacitors in active-matrix displays could also be very useful to analyze the quality of the dielectric-semiconductor interface in field effect devices (Khan, Bhansali, \& Alshareef, 2011; Xian \& Yoon, 2009; Yu, Li, Zhang, Sun, \& Zheng, 2015; Zhang et al., 2015).

The use of transparent electrodes is key for developing transparent electronic devices, in which indium tin oxide (ITO)

\footnotetext{
* Corresponding author.

E-mail address: madominguezj@gmail.com (M.A. Dominguez).
}

Peer Review under the responsibility of Universidad Nacional Autónoma de México. has been most commonly used. However, because of the high demand of indium, the use of ITO will be economically unviable. Therefore, much research is under development to find alternatives to ITO. On the other hand, in addition to the unviability of ITO, the typically used deposition techniques involve high vacuum, present incompatibility with large-area substrates and high-cost. For these reasons, solution-process techniques have become very attractive because of their lowcost, simplicity, compatibility with large-area substrates and the film deposition under ambient conditions. It is important to mention that the consecutive solution-deposition of thin films to fabricate semiconductor devices has been a great challenge (Hunter et al., 2015). In this work, we present fully solution-processed zinc oxide metal-insulator-semiconductor (MIS) capacitors employing the ultrasonic spray pyrolysis and spin-coating techniques. Fluorine tin oxide and spin-on glass are used as transparent electrode and dielectric film, respectively.

\section{Experiment}

The films were deposited using a typical home-made ultrasonic spray pyrolysis (USP) deposition system adapted from 

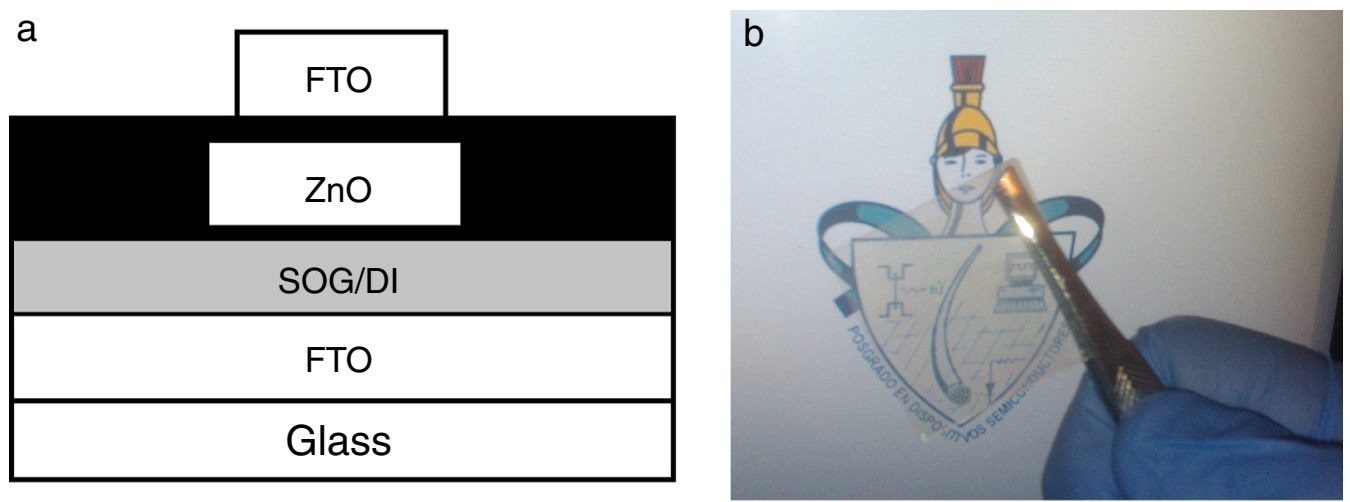

Fig. 1. ZnO MIS capacitor structure. (a) Schematic cross section and (b) photograph of the fabricated devices.

an ultrasonic humidifier (Heaven Fresh). The transparent electrodes were obtained using fluorine tin oxide (FTO) from $0.2 \mathrm{M}$ precursor solution of tin tetrachloride pentahydrate in ethanol with ammonium fluoride diluted in deionized water prepared with $\mathrm{F} / \mathrm{Sn}$ ratio of 0.52 . The $\mathrm{ZnO}$ was obtained using $0.2 \mathrm{M}$ precursor solution of zinc acetate in methanol. The transparent dielectric was obtained using a spin-on glass solution (SOG700B Filmtronics) diluted 3:1 with deionized water (DI) and spin coated onto the samples (Dominguez, Rosales, Torres, Moreno, \& Orduña, 2012; Dominguez, Obregon, \& Luna-Lopez, 2016).

The orientation of the film was investigated using an X-ray diffractometer (XRD) (Discover D8-Bruker AXS) at $2 \theta$ range between $20^{\circ}$ and $70^{\circ}$ and $0.002^{\circ}$ step. For the photoluminescence spectroscopy, a laser of He-Cd with $325 \mathrm{~nm}$ line was used as exciting source. The photoluminescence measurement was performed using a silicon PIN Thorlabs (DET-210) detector with a spectral response of 200-1100 nm. The conventional lock-in technique was employed seeking to minimize the effect of noise. The voltage signal was acquired with a Computer Boards CIODAS08 data acquisition card, which operates in conjunction with a stepper motor controller to position the monochromator Sciencetech 9040 to the appropriate wavelength.

The IR absorption spectra of the films were measured with a Brucker FTIR Vertex-70 spectrometer. The IR spectrum was observed for wave numbers between 3500 and $400 \mathrm{~cm}^{-1}$.

To fabricate the transparent MIS capacitors, glass slides were used as substrates. The glass substrates were chemically cleaned. First, they were cleaned in acetone for $10 \mathrm{~min}$, followed with isopropyl alcohol, also for $10 \mathrm{~min}$, in an ultrasonic bath. Finally, the substrates were rinsed with deionized water. After that, FTO deposited by USP was used as bottom transparent electrode. Then, the SOG/DI dielectric film was spin-coated onto the samples at room temperature at $3000 \mathrm{rpm}$ for $30 \mathrm{~s}$. The samples were annealed at $100^{\circ} \mathrm{C}$ for $15 \mathrm{~min}$ to reduce humidity and evaporate most of the solvents, to finally be annealed for $5 \mathrm{~h}$ at $200{ }^{\circ} \mathrm{C}$ in air ambient. Afterwards, as active layer, $\mathrm{ZnO}$ was deposited by USP using air as carrier gas at flow rate of $467 \mathrm{sccm}$ on a hotplate at $200^{\circ} \mathrm{C}$. Finally, FTO was deposited by USP as the top transparent electrode through a shadow mask. The MIS capacitors have an area of $0.002 \mathrm{~cm}^{2}(1 \mathrm{~mm} \times 0.2 \mathrm{~mm})$. The thickness of the $\mathrm{ZnO}$ and SOG/DI films was $350 \pm 15 \mathrm{~nm}$ and $44 \pm 5 \mathrm{~nm}$, respectively.

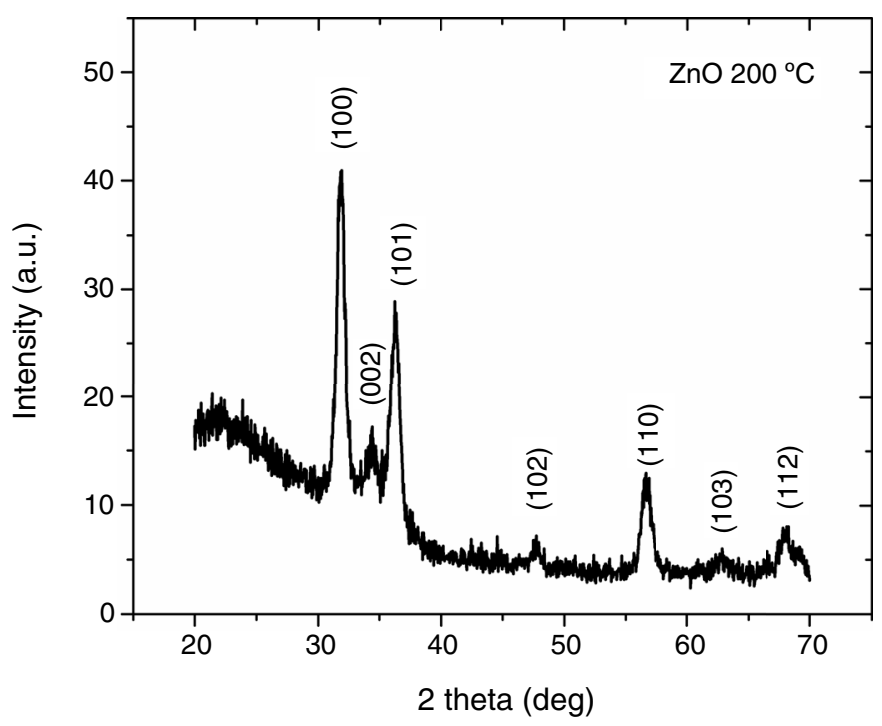

Fig. 2. XRD pattern of the as-deposited $\mathrm{ZnO}$ films by ultrasonic spray pyrolysis.

The capacitance-voltage characteristics were measured using the Keithley-4200 semiconductor characterization system equipped with the 4200-CVU integrated $C-V$, under dark conditions, air ambient and room temperature. The measurements here reported are representative of 9 capacitors. The measurements present a fluctuation lower than the $\pm 10 \%$ on the accumulation capacitance and breakdown voltage.

\section{Results and discussion}

Fig. 1 shows the schematic cross section of the ZnO MIS capacitors and a top-view photograph of the MIS capacitors. The MIS capacitors are highly transparent, which makes their use feasible in transparent electronics.

Fig. 2 shows the XRD pattern of the $\mathrm{ZnO}$ film. The peaks related to the planes (100), (002), (101), (102), (110), (103) and (112) can be identified according with the JCPDS Card No. 36-1451, where the strongest peak is associated to the (100) plane. The XRD diffractogram shows a polycrystalline nature regardless of the low deposition temperature.

Fig. 3 shows the room temperature photoluminescence (PL) spectra of the $\mathrm{ZnO}$ film. It shows a PL spectrum with a peak 


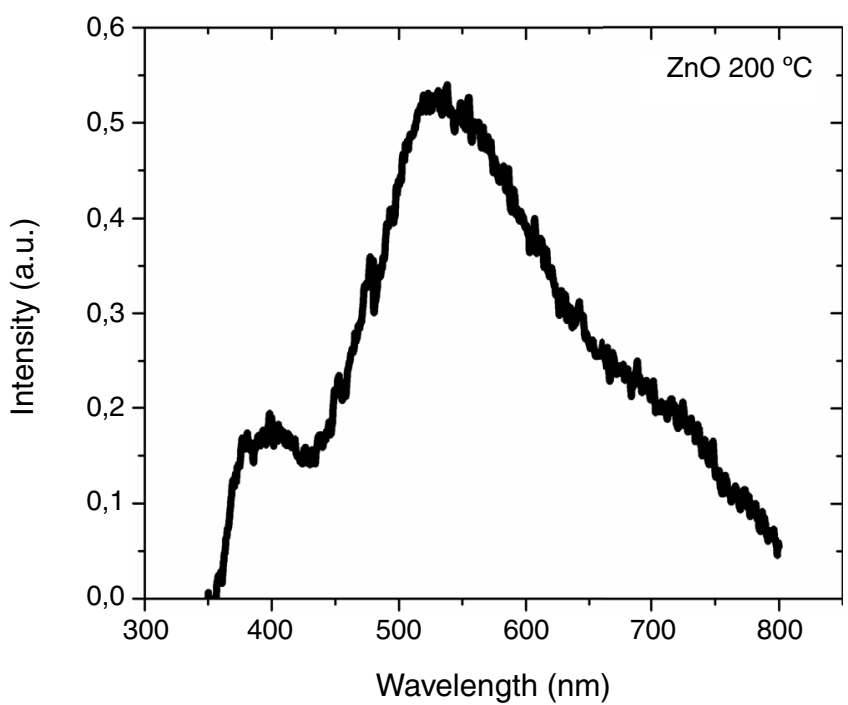

Fig. 3. Photoluminescence of the as-deposited $\mathrm{ZnO}$ films by ultrasonic spray pyrolysis.

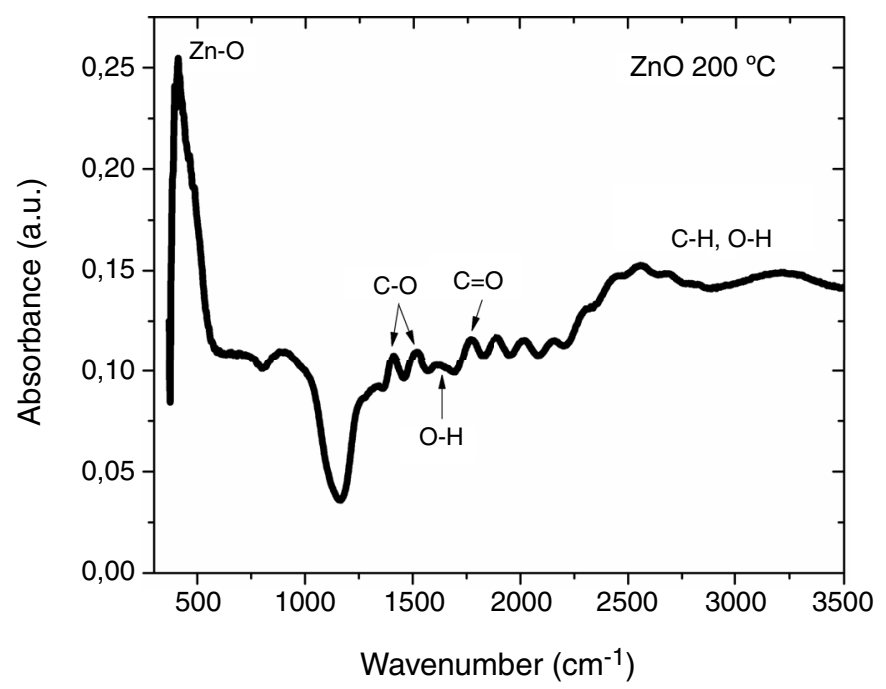

Fig. 4. FTIR spectra of the as-deposited $\mathrm{ZnO}$ films by ultrasonic spray pyrolysis.

centered at $390 \mathrm{~nm}$ and a high intensity broad band from 450 to $700 \mathrm{~nm}$. The UV emission peak at $390 \mathrm{~nm}$ is associated with the near band-edge (NBE) emission of the wide gap attributed to the recombination of the free excitons (Padilla-Rueda, Vadillo, \& Laserna, 2012; Sepulveda-Guzman et al., 2010; Xiao, Zhao, Liu, \& Lian, 2013). The visible emission broad band from 450 to $700 \mathrm{~nm}$ includes the defects and impurities, which are considerable in our case. The origin of this visible emission band may be attributed to oxygen vacancies, zinc vacancies, oxygen antisites, zinc antisites, oxygen interstitial and zinc interstitial (Janotti \& Van de Walle, 2007; Lin, Fu, \& Jia, 2001; Wang et al., 2006).

Fig. 4 shows the FTIR spectra of the $\mathrm{ZnO}$ film. The peak can be observed at $415 \mathrm{~cm}^{-1}$ related to $\mathrm{Zn}-\mathrm{O}$ stretching modes (Adamopoulos et al., 2011; Gayen, Sarkar, Hussain, Bhar, \& $\mathrm{Pal}, 2011)$. The peak at $1627 \mathrm{~cm}^{-1}$ is attributed to $\mathrm{O}-\mathrm{H}$ bending modes. Also, the peaks at $2500-3500 \mathrm{~cm}^{-1}$ are due to $\mathrm{C}-\mathrm{H}$ and O-H stretching modes (Adamopoulos et al., 2011; Gayen et al., 2011). The peaks at $1413 \mathrm{~cm}^{-1}$ and $1530 \mathrm{~cm}^{-1}$ are attributed to

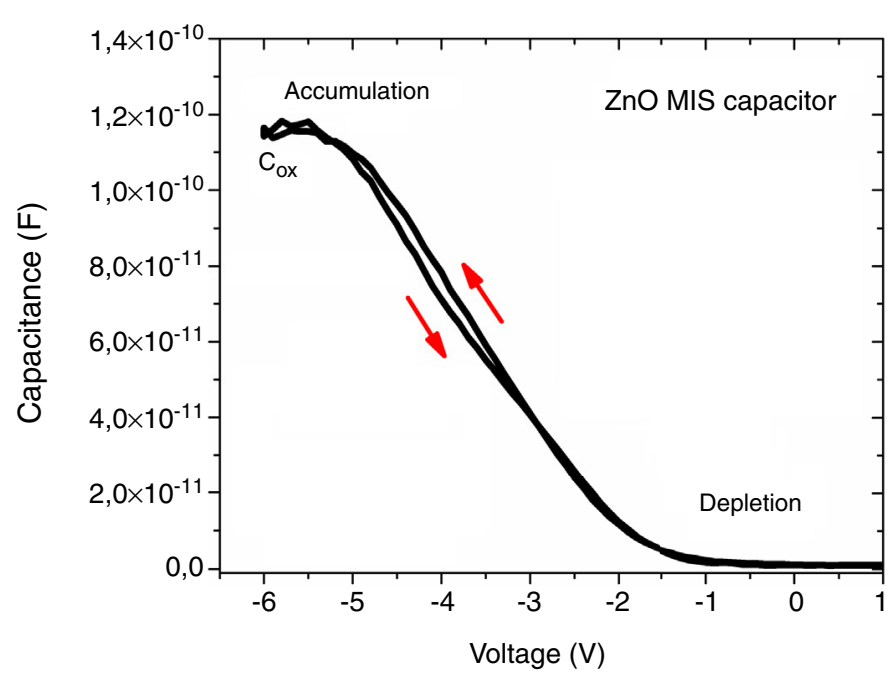

Fig. 5. Forward and reverse capacitance-voltage curves of the ZnO MIS capacitors using FTO and SOG/DI films as transparent electrode and dielectric, respectively.

$\mathrm{C}-\mathrm{O}$ stretching modes, while at $1750 \mathrm{~cm}^{-1}$ they are attributed to $\mathrm{C}=\mathrm{O}$ bonds (Adamopoulos et al., 2011; Gayen et al., 2011). The presence of $\mathrm{C}-\mathrm{O}$ bonds suggests an incomplete precursor pyrolysis due to the low deposition temperature (Adamopoulos et al., 2011). However, the characteristic $\mathrm{Zn}-\mathrm{O}$ band, approximately at $415 \mathrm{~cm}^{-1}$, indicates the $\mathrm{ZnO}$ formation. On the other hand, it is important to mention that bonds related to $\mathrm{O}-\mathrm{H}$ stretching have been previously reported in $\mathrm{ZnO}$ films, indicating the presence of $\mathrm{O}-\mathrm{H}$ complexes that are associated with different defects and increased free-carrier concentration (Adamopoulos et al., 2011; Gayen et al., 2011; McCluskey, Jokela, Zhuravlev, Simpson, \& Lynn, 2002; Shi et al., 2005). This agrees with what was observed in the photoluminescence spectra. Although the $\mathrm{ZnO}$ films need to be improved, the films have been successfully used in TFTs fabricated in silicon wafers (Dominguez et al., 2015; Dominguez-Jimenez et al., 2015). Further research is necessary to optimize the $\mathrm{ZnO}$ film.

Fig. 5 shows the capacitance-voltage characteristics at $10 \mathrm{kHz}$ for the MIS capacitors. When a negative voltage is applied at the top contact, there is an accumulation layer of electrons in the $\mathrm{ZnO}$ film at the SOG/DI-ZnO interface, as a result, the capacitance-voltage characteristics show the dielectric capacitance (Cox). On the other hand, when a positive voltage is applied at the top contact, the characteristics show a minimum capacitance due to the depletion region in the $\mathrm{ZnO}$ film at the SOG/DI-ZnO interface. From the capacitance-voltage characteristics, it can be observed that there is a very low hysteresis when the characteristics are forward and reverse measured. Nevertheless, at negative voltage values, the accumulation region presents effects of interface states (Neamen, 2003). This is attributed to the defects in the $\mathrm{ZnO}$ film near the dielectricsemiconductor interface, as the photoluminescence and FTIR spectroscopies show. Despite this, the MIS capacitors display a similar behavior compared to the capacitance-voltage curves in ZnO TFTs fabricated in silicon wafers with thermally grown silicon oxide as gate dielectric (Bang et al., 2011). 


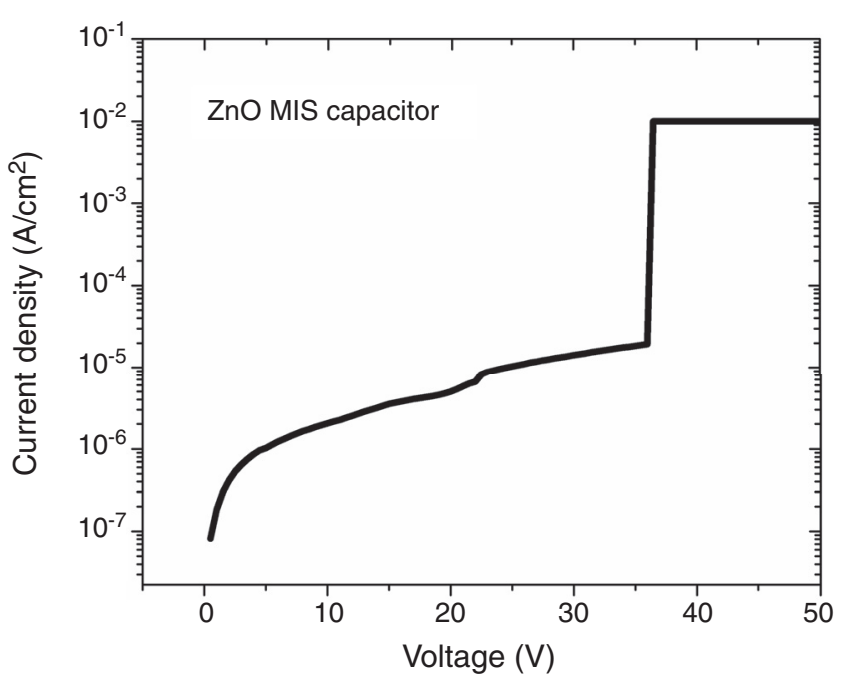

Fig. 6. Current density of the $\mathrm{ZnO}$ MIS capacitors indicating the capacitor breakdown voltage at $36 \mathrm{~V}$.

Fig. 6 shows the current density of the ZnO MIS capacitors. Typically, in solution-processed devices, the evaporation of solvents during the deposition of the films induces pores and lower density in the film which affect the electrical characteristics of the devices (Yoo et al., 2013). The breakdown voltage of the MIS capacitor can be observed at $36 \mathrm{~V}$ because of the dielectric breakdown. Although a higher capacitor breakdown voltage was expected, the values of current density and capacitor breakdown voltage obtained are reliable for electronic devices applications (Park et al., 2013; Yoo et al., 2013).

From the overall characteristics presented, ZnO MIS capacitors can be explored to be used in transparent electronics. $\mathrm{ZnO}$ MIS capacitors were fabricated employing simple and low-cost solution-process techniques with no-vacuum needed, using feasible and easily-prepared precursor solutions.

\section{Conclusions}

In summary, the development of fully solution-processed zinc oxide metal-insulator-semiconductor capacitors employing the ultrasonic spray pyrolysis and spin-coating techniques was successfully presented. Fluorine tin oxide and spin-on glass were used as transparent electrode and dielectric film, respectively. The MIS capacitors were highly transparent, which their use makes feasible in transparent electronics. The capacitance-voltage characteristics showed a very low hysteresis when the characteristics were forward and reverse measured. The accumulation region presents effects of interface states attributed to the defects in the $\mathrm{ZnO}$ film near the dielectricsemiconductor interface, as the photoluminescence and FTIR spectroscopies showed.

\section{Conflict of interest}

The authors have no conflicts of interest to declare.

\section{Acknowledgment}

The authors would like to thank NPTC-PRODEP by SEPMexico and Ciencia Basica SEP-CONACYT grant no. 256513 for funding for this project.

\section{References}

Adamopoulos, G., Bashir, A., Gillin, W. P., Georgakopoulos, S., Shkunov, M., Baklar, M. A., et al. (2011). Structural and electrical characterization of $\mathrm{ZnO}$ films grown by spray pyrolysis and their application in thin-film transistors. Advanced Functional Materials, 21(3), 525-531.

Bang, S., Lee, S., Park, J., Park, S., Ko, Y., Choi, C., et al. (2011). The effects of post-annealing on the performance of $\mathrm{ZnO}$ thin film transistors. Thin Solid Films, 519(22), 8109-8113.

Bashir, A., Wöbkenberg, P. H., Smith, J., Ball, J. M., Adamopoulos, G., Bradley, D. D., et al. (2009). High-performance zinc oxide transistors and circuits fabricated by spray pyrolysis in ambient atmosphere. Advanced Materials, 21(21), 2226-2231.

Dominguez, M., Rosales, P., Torres, A., Moreno, M., \& Orduña, A. (2012). Study of dilution of spin-on glass by Fourier transform infrared spectroscopy. Thin Solid Films, 520(15), 5018-5020.

Dominguez, M. A., Flores, F., Luna, A., Martinez, J., Luna-Lopez, J. A., Alcantara, S., et al. (2015). Impact of active layer thickness in thin-film transistors based on zinc oxide by ultrasonic spray pyrolysis. Solid-State Electronics, 109, 33-36.

Dominguez-Jimenez, M. A., Flores-Gracia, F., Luna-Flores, A., MartinezJuarez, J., Luna-Lopez, J. A., Alcantara-Iniesta, S., et al. (2015). Thin-film transistors based on zinc oxide films by ultrasonic spray pyrolysis. Revista mexicana de física, 61(2), 123-126.

Dominguez, M. A., Obregon, O., \& Luna-Lopez, J. A. (2016). Study of stability of solution-processed dielectric film under electrical stress. Journal of Alloys and Compounds, 688, 893-896.

Gayen, R., Sarkar, K., Hussain, S., Bhar, R., \& Pal, A. (2011). Zno films prepared by modified sol-gel technique. Indian Journal of Pure \& Applied Physics (IJPAP), 49, 470-477.

Hunter, B. S., Ward, J. W., Payne, M. M., Anthony, J. E., Jurchescu, O. D., \& Anthopoulos, T. D. (2015). Low-voltage polymer/small-molecule blend organic thin-film transistors and circuits fabricated via spray deposition. Applied Physics Letters, 106(22), 223304-1-223304-4.

Janotti, A., \& Van de Walle, C. G. (2007). Native point defects in ZnO. Physical Review B, 76(16), 165202.

Khan, M. A., Bhansali, U. S., \& Alshareef, H. N. (2011). Fabrication and characterization of all-polymer, transparent ferroelectric capacitors on flexible substrates. Organic Electronics, 12(12), 2225-2229.

Langley, D., Giusti, G., Mayousse, C., Celle, C., Bellet, D., \& Simonato, J. P. (2013). Flexible transparent conductive materials based on silver nanowire networks: A review. Nanotechnology, 24(45), 452001.

Lin, B., Fu, Z., \& Jia, Y. (2001). Green luminescent center in undoped zinc oxide films deposited on silicon substrates. Applied Physics Letters, 79(7), 943-945.

McCluskey, M. D., Jokela, S. J., Zhuravlev, K. K., Simpson, P. J., \& Lynn, K. G. (2002). Infrared spectroscopy of hydrogen in ZnO. Applied Physics Letters, 81(20), 3807-3809.

Neamen, D. (2003). Semiconductor physics and devices (3rd ed., pp. 474-483). McGraw Hill.

Padilla-Rueda, D., Vadillo, J. M., \& Laserna, J. J. (2012). Room temperature pulsed laser deposited $\mathrm{ZnO}$ thin films as photoluminescence gas sensors. Applied Surface Science, 259, 806-810.

Park, J. H., Yoo, Y. B., Lee, K. H., Jang, W. S., Oh, J. Y., Chae, S. S., et al. (2013). Low-temperature, high-performance solution-processed thin-film transistors with peroxo-zirconium oxide dielectric. ACS Applied Materials \& Interfaces, 5(2), 410-417.

Sepulveda-Guzman, S., Reeja-Jayan, B., De la Rosa, E., Ortiz-Mendez, U., Reyes-Betanzo, C., Cruz-Silva, R., et al. (2010). Room-temperature 
deposition of crystalline patterned $\mathrm{ZnO}$ films by confined dewetting lithography. Applied Surface Science, 256(11), 3386-3389.

Shi, G. A., Stavola, M., Pearton, S. J., Thieme, M., Lavrov, E. V., \& Weber, J. (2005). Hydrogen local modes and shallow donors in ZnO. Physical Review $B, 72(19), 195211$

Wang, D., Seo, H. W., Tin, C. C., Bozack, M. J., Williams, J. R., Park, M., et al. (2006). Effects of postgrowth annealing treatment on the photoluminescence of zinc oxide nanorods. Journal of Applied Physics, 99(11), 113509.

Xian, C. J., \& Yoon, S. G. (2009). Transparent capacitor for the storage of electric power produced by transparent solar cells. Journal of the Electrochemical Society, 156(11), G180-G183.

Xiao, S. S., Zhao, L., Liu, Y. H., \& Lian, J. S. (2013). Nanocrystalline ZnO films prepared by pulsed laser deposition and their abnormal optical properties. Applied Surface Science, 283, 781-787.
Yoo, Y. B., Park, J. H., Lee, K. H., Lee, H. W., Song, K. M., Lee, S. J., et al. (2013) Solution-processed high-k $\mathrm{HfO}_{2}$ gate dielectric processed under softening temperature of polymer substrates. Journal of Materials Chemistry C, 1(8), $1651-1658$.

Yu, S., Li, L., Zhang, W., Sun, Z., \& Zheng, H. (2015). Fully transparent thin-film varactors: Fabrication and performance. Journal of Materials Chemistry $C$, 3(22), 5703-5708.

Zhang, G., Wu, H., Chen, C., Wang, T., Yue, J., \& Liu, C. (2015). Transparent and flexible capacitors based on nanolaminate $\mathrm{Al}_{2} \mathrm{O}_{3} / \mathrm{TiO}_{2} / \mathrm{Al}_{2} \mathrm{O}_{3}$. Nanoscale Research Letters, 10(1), 76.

Zhu, H., Fang, Z., Preston, C., Li, Y., \& Hu, L. (2014). Transparent paper: Fabrications, properties, and device applications. Energy \& Environmental Science, 7(1), 269-287. 